\title{
Críticas aos fundamentos filosóficos, sociológicos e históricos do currículo do magistério de $2^{\circ}$ grau
}

\author{
Elpídio M. Cardoso* \\ José Vicente Miranda \\ Virginia Anne van den Berg
}

\section{Introdução}

Resultante de um estudo realizado no decorrer de 1991, por um grupo de professores do Departamento de Teoria e Fundamentos da Educação do Setor de Educação da UFPR, preocupados com a concepção da pedagogia histórico-crítica adotada pela Secretaria de Estado da Educação, quanto aos fundamentos filosóficos, sociológicos e históricos do Currículo do Magistério de $2^{\circ}$ grau, as reflexões ora apresentadas visam a abertura do debate face aos diferentes pontos de vista teórico-práticos na formação do Educador-Pedagogo.

* Doutor em Filosofia. Professor Titular Departamento de Teoria e Fundamentos da Educação - UFPR.

Mestre em Sociologia. Professor Adjunto do Departamento de Teoria e Fundamentos da Educação - UFPR.

Mestre em Educação. Professor Assistente do Departamento de Teoria e Fundamentos da Educação-UFPR. 
Entendendo o Educador-Pedagogo como co-responsável pela transmissão e construção do saber universal é fundamental que, a partir da experiência (histórica) superem-se paradigmas parciais e que se proponham novos caminhos na dialética permeada de contradições e sínteses necessárias, no processo de tensões ideológico-axiológicas que caracterizam a educação no seu conjunto.

Não se trata de substituir um "modelo" por outro vencendo-o, afastando-o, removendo-o ou subjugando-o, o que caracteriza uma situação de domínio, mas de adesão às finalidades da educação pública, gratuita $\mathrm{e}$ de qualidade. Nesse sentido convém lembrar que o modelo, 'seja ele qual for, "não é construído a partir do real concreto, do fenômeno, mas de uma representação intelectual desse fenômeno: ele é uma abstração". (REALE, M.). ${ }^{1}$

Por outro lado, o grupo considera fundamental a redefinição dos valores e clara identificação dos fins da formação do Educador, independentemente do modelo-teórico politicamente adotado nos cursos de preparação para o Magistério de $2^{\circ}$ Grau no Estado do Paraná. Cabe refletir sobre a máxima "os meios justificam os fins", assim como, a assertiva de Nietzche, ${ }^{2}$ de que nossa civilização ao subordinar os fins aos meios, avança aceleradamente para um despenhadeiro. Ou ainda, relembrando Furtado, ${ }^{3}$ para quem todo o processo de concentração do poder engendra burocratização, que outra coisa não é senão a tomada de consciência do poder por aqueles que têm o controle dos instrumentos desse poder, e, mais adiante, afirma o mesmo autor: o difícil que sempre foi submeter à disciplina aqueles que exercem o poder em nome de outrem.

Sendo a educação brasileira historicamente resultado de interesses político-partidários de grupos ideologicamente

constituídos, cabe-nos, enquanto professores das disciplinas intituladas de fundamentos da educação, propiciar a abertura ao diálogo e debate sobre as questões da formação do Educador (Magistério - $2^{\circ}$ grau e Pedagogia $-3^{\circ}$ grau). Considera-se, sem dúvida, que as bases metodológicas e os conceitos filosófico-teórico-práticos desenvolvidos no currículo de $2^{\circ}$ grau refletem na atuação dos acadêmicos de $3^{\circ}$ grau. No entanto, essas bases não podem assumir uma visão de parcialidade, interpretando a educação como resultante apenas das relações capital-trabalho; assim, como seria parcial a interpretação da realidade sob a óptica

1 REALE, Miguel. Estudos de filosofia e ciência do direito.

2 NIETZCHE, Friedrich. Ecce Homo.

3 FURTADO, Celso. Criatividade e dependência na civilização industrial. 
histórico-materialista, fenomenológica, estruturalista, behaviorista, existencialista ou positivista somente.

É necessário "reaprender a ver o mundo", ${ }^{4}$ leitura essa, função básica da filosofia na compreensão, interpretação e transformação das relações homem-mundo.

O educador necessita de fundamentos teóricos amplos, para que possa construir seu próprio referencial sem ater-se a meros discursos ideológicos dependentes da alternância de grupos políticos temporariamente no poder.

Finalmente, convém libertar-se dos grilhões da unilateralidade partidária, dos slogans tipo: "tudo pelo social", - "opção pelos pobres"; "educação para a classe trabalhadora" - "trabalhadores da educação" e tantos outros. Por sua própria forma o assim chamado "compromisso político" acaba marginalizando quaisquer outros pontos de vista não só criticando, mas negando a validade científica de outras concepções pedagógicas construídas no decorrer da história. Afinal o estado democrático se faz mediante a convivência dos contrários, determinados pela circunstância espaço-temporal de cada civilização. Todos somos cidadãos da polis, com deveres e direitos explícitos na Magna Carta. Cabenos possibilitar aos discentes dos cursos de Magistério de $2^{\circ}$ grau e de Pedagogia $3^{\circ} \mathrm{Grau} / \mathrm{UFPR}$, uma ampla visão dos conteúdos das disciplinas de Sociologia da Educação, Filosofia da Educação, História da Educação para que se engajem no processo de construção do conhecimento científico. As revoluções, sempre fundamentadas por idéias válidas circunstancialmente, perdem-se, à medida em que o timoneiro deixa-se levar pela maré ou pelos ventos, perdendo de vista seu principal objetivo que é o próprio homem.

\section{Três pontos de vista}

As reflexões aqui apresentadas, respeitando os diferentes estilos de redação dos autores, visam contribuir à ampliação do espaço de discussão acadêmico em torno das diferentes concepções e tendências pedagógicas na formação do Educador, numa tentativa de buscar um

4 MERLEAU-PONTY, M. $O$ visivel e o invisivel. 
caminho nosso, brasileiro, sem amarras em ideologias alienígenas à nossa realidade.

\begin{abstract}
A ideologia não é um erro local, explicável psicologicamente, mas uma estrutura de pensamento vinculada a um grupo, a uma classe social, a uma nação. (MANNHEIM, Karl). ${ }^{5}$
\end{abstract}

Ao se tratar dos Fundamentos filosóficos, sociológicos e históricos do Currículo do Magistério de $2^{\circ}$ Grau tem-se como principal preocupação a Formação do Educador atuante no ensino de $1^{\circ}$ Grau que é , basicamente, $o$ aluno do Curso de Pedagogia desta Universidade.

Sendo estas disciplinas (Filosofia, Sociologia e História) componentes obrigatórios do Currículo Pleno do Curso de Pedagogia e ainda, instrumentos fundamentais para a reflexão e interpretação do conhecimento com vistas à construção do saber pedagógico, cabe-nos expressar as preocupações e críticas quanto à concepção de educação que vem sendo "trabalhada", desde o ensino de $2^{\circ} \mathrm{Grau}$, na formação dos nossos pedagogos.

Entendemos que o pedagogo deva percorrer o caminho da reflexão filosófica, através da sociologia do conhecimento e da filosofia da história, para que possa construir argumentos científicos transformadores da realidade. Para tanto é fundamental a compreensão das raízes da educação brasileira nos seus determinantes históricos bem como dos componentes ideológicos que estruturam a realidade educacional. Nem se pode negar o caráter de dependência do sistema educacional que se reflete na alternância do poder. A Educação Brasileira continua sendo "moldada" segundo os interesses da política dominante.

Assim sendo, é posta em questão a visão unilateral que julga verdadeira apenas UMA CONCEPÇÃO DE EDUCAÇÃO, que se fundamenta na opção política de um pequeno grupo que busca a manutenção do poder. Poder este passageiro pois que se fundamenta em idéias que se fecham em si mesmas por não aceitarem a contra-argumentação. A esse respeito convém lembrar que sempre haverá uma contra-ideologia (GRAMSCI) ${ }^{6}$ e que Platão, ${ }^{7}$ na alegoria da caverna (A República), já buscava demonstrar a importância de ver além dos reflexos e imagens das coisas.

Parece-nos que o mundo dos educadores encontra-se dividido entre "liberais" e "progressistas", não havendo espaço para os profissionais cansados de "ismos" e de "istas". Queremos a transformação do curso de

5 MANNEIM, Karl. Ideologia e Utopia.

6 GRAMSCI, A. In: Manacorda. O princípio educativo em Gramsci.

7 PLATÃO. A República. 
Pedagogia, das suas disciplinas fundamentais, queremos liberdade de opção metodológica e queremos o diálogo como instrumento de construção do SABER.

Estamos cansados do "discurso" "pedagolítico" e das críticas vazias de conteúdo filosófico, sociológico e histórico, no entanto, direcionadas a uma concepção assim chamada histórico-crítica que se fundamenta numa visão materialista da história. Não se pode perceber a realidade apenas de um ponto de vista ou perspectiva.

Nesse sentido criticamos, também, as teorias chamadas estruturalistas ou funcionalistas que cobram o "behaviorismo" dos alunos, não permitindo interpretações próprias e refletidas. $O$ discurso funcionalista fechado também contém sua carga ideológica de acrítica e autoritária, quando só admite uma ciência "pseudoneutra" ausente e distante da realidade social, cultural, econômica do país e, mais grave, da criança que é o agente fundamental no e do trabalho do pedagogo.

$O$ educador seja pedagogo, seja licenciado, atuante no ensino de $1^{\circ}$, $2^{\circ}$ e $3^{\circ}$ Graus de ensino formal brasileiro deve ter uma consciência crítica para transformar sua ação pedagógica num instrumento de construção e reconstrução do processo de conhecimento sem o qual não há Civilização.

Diante do exposto, e da análise realizada quanto aos conteúdos dos Fundamentos da Educação referentes à Filosofia, à Sociologia e à História, atualmente desenvolvidos no Curso de Magistério de $2^{\circ} \mathrm{Grau}$, temos como pressuposto básico a urgência na revisão dos conteúdos, considerando fundamental a ampliação das concepções, possibilitando uma análise crítica que seja "capaz de ver além das coisas" (NIETZSCHE) longe dos "pacotes pedagógicos" elaborados em gabinetes e em função de interesses de poucos em detrimento de muitos. A verdadeira democracia se constrói com a efetiva participação (ROUSSEAU). ${ }^{9}$ Só aceita a mudança quem dela participa. Para tanto, é necessário compreender a realidade e transformá-la com o conhecimento, que é o instrumento fundamental do SABER. As ideologias estão por cair dos galhos da História (CARDOSO); ${ }^{10}$ é nossa tarefa construir as condições para a convivência dos contrários, buscando nos Fundamentos da Filosofia, da Sociologia e da História os melhores caminhos para a nossa atuação como educadores.

8 NIETZCHE, F. Assim Falou Zaratrusta.

9 ROUSSEAU, Jean Jacques. $O$ contrato social.

10 CARDOSO, A ideologia e as ciências humanas. 
Para tanto, nossos alunos devem ter segurança para discernir e optar entre as diferentes concepções de educação, relacionando as diferentes circunstâncias históricas com o presente para poderem transformar o futuro.

Preocupa-nos, nesse sentido, a opção política com referência a um único projeto global para o magistério, opção esta que não está isenta da lei do conflito que se provoca em toda decisão política. Ora, toda planificação democrática implica necessariamente numa reflexão global que vise diminuir as diferenças entre os interesses individuais e coletivos, tomando como base princípios comuns.

Sabemos que é ilusório que todos se porão facilmente de acordo com as propostas pedagógicas ora em foco, assim como é um erro acreditar e mesmo esperar que todos partilhem das críticas aqui expostas. Sempre haverá a contradição e antagonismos que fazem parte da dinâmica social criada pelo homem. Mas há um preço a pagar: a impotência de influir sobre a sociedade (RICOEUR); ${ }^{11}$ somos responsáveis como educadores a provocar, inquietar e lançar as sementes de mudança. Devemos ousar a provocar o debate!

Estas reflexões tem por pano de fundo comum os conteúdos das disciplinas acadêmicas conhecidas como "Fundamentos da Educação". E já que existe no Setor de Educação da UFPR um Departamento que se dedica a ensinar esses fundamentos (Departamento de Teoria e Fundamentos da Educação), não é indiferente aos componentes que sobre eles escrevem, o teor da discussão ventilado nos conteúdos propostos aos alunos que se preparam para o magistério ao nível de $2^{\circ} \mathrm{Grau}$.

As críticas ora apresentadas são concepções da vida e portanto, de discursos diferentes, as quais, entretanto, é preciso que sejam ditas, para se sair da espiral ilusória de se tomar a parte pelo todo e vice-versa.

Tais reflexões não pretendem se apropriar da verdade ou da parte dela existente nos programas veiculados pela SEED para os alunos do Magistério, mas apenas lhes proporcionar o conhecimento do reverso da medalha, para que, desta maneira, eles o possam recuperar para a sua formação. Do contrário parece que adotaríamos uma posição pouco "paidêutica". O mesmo vale para os estagiários licenciados em fase de treinamento para o ensino dessas disciplinas no futuro.

Alguns professores do ensino secundário se mostraram curiosos e até mesmo surpresos quando se lhes disse que poderia surgir um espaço de reflexão crítica a propósito dos programas propostos. Se fazia, então,

11 RICOEUR, P. Interpretação e Ideologias. 
sentir uma necessidade desta tentativa de desvelamento dos meandros da semântica da Pedagogia em seus Fundamentos. As presentes reflexões abrem esse espaço com uma ponta de esperança expressa naquele aforismo hindu: "A Verdade acaba triunfando" (SATYA MEV JAYATÊ).

Pois bem, é dentro desse espírito crítico que se apresentam as reflexões quanto ao sentido dos Fundamentos Filosóficos, Sociológicos e Históricos no Curso de Formação para o Magistério e, conseqüentemente na formação do EDUCADOR.

\section{Sentido da filosofia da educação no curso de Pedagogia}

\section{Elpídio Marculino Cardoso}

Consideramos a filosofia o exercício do pensamento livre. Ela não deve apenas conhecer o que disseram os pensadores. Ela precisa criar o pensamento. Este é o seu compromisso histórico, desde Pitágoras, que formulou o seu nome: filos + sofia (o amigo da sabedoria).

Sendo a sabedoria ampla, abrangente e evolutiva, está na criatividade do pensamento humano a vida da filosofia.

A filosofia da educação, considerada esta uma atividade social de comunicação e a filosofia da pedagogia, como inspiradora das ciências da educação, são o exercício livre e criativo das inteligências pensantes que destas realidades se preocupam.

No livre exercício do pensamento que gera a filosofia e que por ela é gerado, deve haver lugar para todas as direções. E dos vetores da roda d'água deste moinho, se expandirá a sabedoria.

Não é apenas na filosofia aristotélico-tomista nem na ideologia do partido único anterior à Perestroika, que se fundamentam as ciências pedagógicas. Mas é na livre expressão das idéias que um novo currículo e uma nova metodologia nascerão. 
A filosofia da pedagogia deve dar base e sustentação à dialética que movimenta num turbilhão todas as idéias. Daí se saberá qual o rumo da biologia, da história, da sociologia e da psicologia da educação.

Sentados à sombra da árvore que é enxerto de todos os frutos do jardim de delícias, lembramos o passado e enxergaremos o futuro.

Nas posições ideológicas fechadas há o preconceito do conceito já feito, desfeito pela sua própria inutilidade. Em toda a idade em que se encontra a criança permanece o elo de ligação e desenvolvimento da sociedade.

O professor que reza sempre a mesma cartilha, encilha a besta pensando que educa: Criar é fazer. Pensar é agir. Educar é ouvir. Quem pensa ter a verdade absoluta não entende que já a Fenomenologia de Kant no reino da Razão Prática, dispensou a certeza dos conhecimentos a priori.

Senhores de si mesmos os alunos da Universidade serão todos juntos filósofos. E os professores com eles aprenderão a pensar e falar. - Na raiz da árvore que forma o novo currículo, a filosofia é a seiva que alimenta as ciências.

No tronco, a antropologia, cercada pela casca verde da comunicação, que se renova quando a casca cai e desaparece. Enaltece todos os galhos a psicologia e a sociologia cobre de folhas as copas elegantes. As flores são as pessoas vivas que a biologia conhece. E a arte de escrever está brilhando no espaço. $\mathrm{O}$ tempo dirá quem vencerá melhor a angústia da existência precária.

E a legendária caravana dos camelos adornará de pausado provimento, o pôr-do-sol do deserto.

Perto se acha o dia da vitória, quando não mais haverá humilhação e guerras de nervos, mas onde todos colocarão seus pensamentos à luz do dia, para formar a filosofia permanente. 


\title{
Considerações em torno dos fundamentos sociologicos Samizdat no 1
}

\author{
José Vicente A. N. Miranda
}

Convidados pelo representante do Departamento de Teoria e Fundamentos da Educação junto à Comissão dos Estágios a nos pronunciarmos sobre a proposta pedagógica que orienta o ensino da sociologia da Educação ao jovem candidato ao Curso do Magistério, no âmbito do Ensino do $2^{\circ} \mathrm{Grau}$, os docentes da disciplina SOCIOLOGIA DA EDUCAÇÃO DA UFPR, se propõem a olhar criticamente esse programa e a debatê-lo. Essa crítica é feita ao pensamento que, em seguida, se desdobra em unidades do programa e não às próprias unidades desse programa. $\mathrm{O}$ que vale para aquele, vale também para estas em sua devida proporção.

"As Relações Sociais Capitalistas", conceito sobre o qual se funda a proposta pedagógica da SEED é apenas um conceito desde uma perspectiva da teoria sociológica da produção econômica: na produção dos bens econômicos, os grupos se apropriam dificilmente dos bens em espécie de outros grupos e a esse respeito Evans Pritchard ${ }^{12} \mathrm{diz}$, por exemplo, ser o caso do roubo do gado entre as seç̧ões tribais dos Nuer, onde essa apropriação toma contornos de luta. Marx, ${ }^{13}$ por seu lado, diz da sociedade neo-industrializada de seu tempo que o dono dos meios de produção se apropria do excedente do capital nas costas do operário e define aquele como capitalista. Porém, dá para ver que esse conceito de relações sociais capitalistas é apenas uma parte da visão sociológica do social, construído segundo as exigências epistemológicas para se constituir em um dos conceitos chaves de leitura do social no materialismo histórico. Tanto isso é verdade, que Max Weber tomando o conceito de "espírito de capitalismo" o constrói não do ponto de vista dos bens econômicos mas dos condicionantes religiosos que o afetaram, conhecidos na Obra de Weber como "a ética protestante". Os afetos ao materialismo histórico até agora

12 PRITCHARD, Evans. Os Nuer, Editora Perspectiva.

13 MARCUSE, H. Razão e Revolução, Rio de Janeiro : Editora Paz e Terra, e ARON, R. La Sociologie Allemande Contemporaine. 
não têm sido, nem são capazes de refutar a tese weberiana. Eis porque a relação de causalidade (determinação) de duas variáveis não deve ser radicalizada e dada como esgotada, por seu princípio ser precário e difícil de resolução, como o faz superficialmente a introdução da Proposta Pedagógica em questão. Nela, o conceito de Educação encontra abrigo, com vista à compreensão da escola, do meio circundante e das relações com a Sociedade só nas relações capitalistas. Até pode ser que o seja! Entretanto, situar o conceito de Educação para o (a) jovem secundarista exclusivamente como fruto das relações capitalistas, é não ceder da sua perspectiva. É negar por exclusão a existência de outros pontos de vista e portanto, absolutizando, incorrer no labirinto ideológico, donde, como o diz Gunther Eisermann ${ }^{14}$ se sai com o argumento: aquele que rejeitar a análise marxista e as conseqüências daí resultantes deve, forçosamente, ter uma falsa consciência, isto é, uma consciência burguesa. Ou você aceita o argumento marxista ou você está laborando em falsa consciência. Não há saída. Essa visão dantesca da sociologia parece ser prejudicial ao seu caráter científico; - a falar da cientificidade de uma tal proposta é tomar a parte pelo todo, parcialidade cujo caráter é escondido o tempo todo não só do leitor da proposta, mas muito mais do seu desprevenido destinatário. Isso reflete o caráter castrador que, parece se pretende impor à Sociologia da Educação. Não é essa a posição dos docentes da mesma disciplina na UFPR, os quais, embora não possam negar desde a sua perspectiva teórica, a relação entre a escola e o capitalismo, nunca a argumentam como existente exclusivamente.

Esta crítica visa, portanto, toda a proposta pedagógica da disciplina comprometida com essa visão na sua parcialidade impedindo, dessa maneira, sob os pretextos mais sagrados, de a inteligência do aluno do $2^{\circ}$ grau, no Brasil, se abrir a outros pontos de vista.

Tal posição não deixa de herdar certo ranço stalinista, porquanto se aproveita da situação de poder para eliminar o pensamento que fosse diferente daquele que dita as regras: será, então, preciso repetir com o conhecimento do aluno secundarista brasileiro a experiência trágica daquelas pessoas que morreram assassinadas por deterem um pensamento diferente do pensamento do ditador? Não se pensava, também, na época da ditadura do proletariado dos anos 20 , em propósitos políticos a serem atingidos tais como os alegados na introdução desta Proposta Pedagógica?

14 EISERMANN, G. In: Duvignaud, J. Sociologie de la Connaissance, Editora Payot : Paris, 1978. 
Uma pedagogia deste jaez irá abrir a inteligência do aluno à compreensão da Escola na Sociedade?

Finalmente, é cabível se perguntar, a modo de conclusão, qual a eficácia deste propósito? Afastada a perspectiva da reprodução pura ou mediata das sociedades, com base na sua ordem simbólica, é possível pensar em uma alternativa ao quadro acima descrito. Nesse sentido se constata que aos conteúdos programáticos constituídos e divulgados por leis e decretos, pela autoridade de uma situação de poder da SEED, se contrapõe o pensamento de alguém que, sem outras mediações e desde a sua condição subterrânea, se aproxima da imagem de um processo já acontecido, o qual se iniciando com os "SAMIZDAT" (literatura underground na antiga URSS) abre um caminho igualmente subterrâneo para a Perestroika do regime. Por isso o inciso do presente trabalho leva ao cabeçalho esse votivo título com o número um.

\section{Proposta curricular da habilitação magistério, referente ao ensino da disciplina de história da educação ${ }^{15}$}

Decorrências da concepção teórica adotada com vistas ao sentido da História da Educação nos currículos dos cursos para a formação de Educadores.

\section{Virginia Anne van den Berg}

À primeira vista, o documento pretende avançar na construção de um currículo capaz de proporcionar a melhoria da formação do professor das séries iniciais. Tem como pontos de referência: a questão da legitimidade da produção do saber; a democratização da escola; a melhoria da qualidade do ensino, envolvendo não só teorias da educação escolar, mas a teoria da produção e formação dos homens na história. No entanto, ao

15 Documento oficial apresentado em maio de 1989, pela Secretaria de Estado da Educação - Departamento do Ensino de $2^{\circ} \mathrm{Grau}$ - Setor de Educação. 
mesmo tempo em que propõe a libertação e incentiva a criatividade, acaba esvaziando-se no comprometimento com uma concepção que se fecha em si mesma.

A proposta fundamenta-se numa única visão de mundo, onde a pedagogia de tendência progressista se transforma num único modelo e regra válida para interpretação da História da Educação. Revela-se assim um posicionamento teórico unilateral semelhante ao tão criticado conservadorismo e tradicionalismo pedagógicos. O verdadeiro sentido da realidade e o pensamento dialético não pode submeter-se a convicções e ideologias, mas fazer crescer os aspectos da tolerância, respeitando-se a individualidade na coletividade. Permeia pelo documento um sistema de preconceito onde a cientificidade e a competência'se mede a partir de maior ou menor compromisso político.

Em decorrência, é clara a desvalorização da educação e dos educadores formados há uma geração. Criticam-se no documento as oportunidades perdidas por força dos "desígnios ditatoriais" sendo a formação para o magistério limitada a "um caldo insosso apelidado de Fundamentos da Educação", ${ }^{16}$ do qual fazem parte a Psicologia, a Biologia, a Sociologia, a História e a Filosofia. Ora, não convém formar julgamentos antes de verificar porque e como a educação vigente passa a contrariar os movimentos que provoca. A dialética da evolução busca ajustar, inovar, adaptar, ultrapassar sem no entanto subestimar o esforço na construção do passado com vistas à transformação do aqui e agora do futuro.

Tudo é dialética no ser que sai de uma concha. E, como não sai inteiro, o que sai contradiz o que fica fechado. $O$ interior do ser fica aprisionado a formas geométricas sólidas. (BACHELARD - A Poética do espaço)

$\mathrm{O}$ "caldo insosso" apelidado de Fundamentos da Educação, responsável pela formação de uma geração de professores "escolanovistas", 17 bem representa o ser que sai de uma concha. Da mesma forma a concepção progressista sob a óptica da interpretação histórico-materialista. Ambas as tendências e/ou concepções são ultrapassadas, na medida em que a história humana busca compreender que os fenômenos tempoespaço resultam do conhecimento construído pelo homem em relação as suas próprias conquistas, avanços, recuos, retrocessos, para conquistar um novo patamar no desenvolvimento da Cultura, da Sociedade, da CiviEDUCAÇÃO.

16 DOCUMENTO SEED P. 1, referente à CONCEPÇÃO DE HISTÓRIA DA 17 Ibidem. 
lização e do Indivíduo; encadeado historicamente pelo conhecimento do homem. Quem constrói esse conhecimento e como o homem o adquire e utiliza? Serão os fundamentos da Educação, o chamado "caldo insosso", responsáveis pela criação desta realidade concreta insossa, materialista característica do final do século XX?

A toda ação corresponde uma reação igual ou contrária. A visão metafísica cede lugar ao materialismo; as relações de trabalho cedem lugar ao princípio do explorador $\mathrm{x}$ explorado; a filosofia cede lugar ao capitalismo. São ações e reações as quais, construídas pelo próprio homem no decorrer dos séculos, terão na revolução que ocorre no aqui e agora, papel fundamental na construção de um patamar no processo de conhecimento.

O homem busca no conhecimento a síntese do ontem, hoje e amanhã e faz do conhecimento o instrumento para a conquista do saber. Se a escola é a instituição que possibilita a socialização deste conbécimento, deve fazê-lo considerando os aspectos da Psicologia, da Biologia, da Sociologia, da História, entre outros, fundamentando-se na Filosofia.

Críticas quanto à qualidade do ensino e seu "conteúdo-pedagógico", enquanto educação formal, já foram expostas por Comenius e E. de Rotterdam, assim como Machiavel e T. Morus expuseram suas denúncias no âmbito político e social. Tiveram a coragem de apresentar a natureza das contradições ao mesmo tempo em que, indicaram caminhos, opções científicas, para a transformação das relações entre o homem e o mundo.

O entendimento da complexidade das relações do homem com o mundo gera antagonismos, avanços, recuos, declínios, repetições cíclicas, causados pelas limitações que caracterizam o homem como ser "racional". O que é válido para a sociedade em determinado tempo e espaço, modifica-se de acordo com as circunstâncias criadas pelo homem e apresentadas pela natureza. Daí, não há como estabelecer uma única concepção de interpretação da realidade histórica. Assim como a refração da luz no cristal mostra a multiplicidade e retorna a unidade, o homem busca seu caminho através do conhecimento para chegar ao saber, que é universal.

Nesse caminho a tendência histórico-materialista é apenas um dos instrumentos para decifrar a esfinge que devora a realidade como resultante da luta de classes, das relações capital - trabalho, dos interesses hegemônicos da ideologia dominante, na óptica do Capital de Marx.

Se, nos termos propostos no documento, a História da Educação ocorre no interior da concepção de educação como processo e a reflexão 
se constitui à rigor, na "filosofia" do programa" ${ }^{18}$ então será: DECIFRAME ou TE DEVORO"!

Idéias e conceitos como: classes dirigentes, dominados, confronto, transformam-se em meros "dogmas místico-religiosos" ou "amálgama de representações" que se descaracterizam pelo senso comum estabelecido em função do referencial apresentado.

A proposta curricular ora apresentada é segregadora por si só quando apresenta um "óculos metodológico". ${ }^{19}$ Ao contrário de propor a construção de uma concepção brasileira de história da Educação, busca nos pergaminhos embolorados da dialética materialista algumas palavras que fazem os "educríticos" e "pedagolíticos" "abanarem as orelhas em sinal de aprovação. " 20 São como as palavras em grego e latim que extasiavam os homens do século XVI!

Assim é que resulta uma proposta curricular para a habilitação magistério, na disciplina de História da Educação, como "óculos metodológicos" - de visão unilateral, sem refração. Proposta que acaba se transformando no monóculo da formação do educador, esquecendo que a educação e a realidade do mundo possuem o princípio do Caleidoscópio; uma visão mais ampla, dialética, abrangente e mutável que obriga os educadores a abrir a concha e soltar também o "interior do ser que fica aprisionado a formas geométricas".

Novos caminhos:

A título de ampliar o debate em busca de novos caminhos na formação do Educador, seja no Magistério de $2^{\circ}$ grau ou no Curso de Pedagogia, o que se propõe é uma reflexão conjunta em torno da responsabilidade de Educar institucionalmente dada à organização escolar pela própria sociedade. As diferentes críticas aqui apresentadas, são nada mais que uma contribuição para a leitura reflexiva das controvérsias que caracterizam, cada vez mais, a opção consciente na composição teórica e ação pedagógica notadamente na última década.

18 DOCUMENTO SEED. p. 5.

19 DOCUMENTO SEED, p. 1.

20 ROTTERDAM, Erasmo de. Elogio da Locura. 
Qual será a pedra angular de sustenção do processo de Educar? Assim como as diferentes notas musicais compõem um conjunto harmônico traduzido em determinada peça musical de estilo único, também a educação resulta de diferentes forças polarizantes. A controvérsia, o debate $e$ a reflexão crítica são pontos de referência que contribuem para a busca da verdade.

A nós, educadores, cabe a tarefa do maestro que diante da orquestra é capaz de interpretar a partitura mantendo a mensagem do autor, sem tendenciosidade e nem deificá-lo transformando-o em mito, ou única verdade histórica. Interpretação essa, que a partir da liberdade individual de opção, resulta em diferentes tendências, não podendo limitar-se a uma única concepção sob pena de descaracterização dos seus fundamentos.

Entendemos que os responsáveis pelo estabelecimento das políticas de educação pública bem como pela sua administração, devam mostrar-se mais receptivos no encaminhamento das questões educacionais pelos diferentes segmentos da sociedade legalmente instituídos e representados.

Propomos a organização de um debate nacional isento de cor político-partidária ou ideológica, onde não se defenderão posições dogmáticas ou radicais, mas uma revisão de posicionamentos. Abertura para receber e fazer críticas referentes à atuação do Estado e dos profissionais voltados à formação do educador.

Prioritariamente é fundamental realizar movimentos de mobilização nacional para fazer cumprir o papel do Estado enquanto responsável pelo dever de proporcionar educação pública, gratuita e de qualidade, nos termos constitucionais explicitados no capítulo III, que trata da Educação, da Cultura e do Desporto, nos seus Artigos 205 a $214 .^{21}$ Somente através do cumprimento da lei que poder-se-á chegar ao equilíbrio Ciência/Filosofia, deixando o parcialismo e a visão fragmentada em busca de soluções amplas e totalizantes, pois a "ciência sem consciência não é senão a ruína da alma. "(Rabelais.) 


\section{REFERÊNCIAS BIBLIOGRÁFICAS:}

ARANHA, Maria Lúcia de Arruda. Filosofando: Introdução à filosofia, São Paulo : Moderna, 1986, $443 \mathrm{p}$.

BRASIL, CONSTITUIÇÃO DA REPÚBLICA FEDERATIVA DO BRASIL, promulgada em 05 de outubro de 1988, São Paulo : Editora Fisco e Contribuinte, $1988,155 \mathrm{p}$.

CARDOSO, Elpídio M. A ideologia e as ciências humanas. Universidade Federal do Paraná, sd, (mim.)

EISERMANN, G. In: Duvignaud, J. Sociologie de la connaissance.

ESTADO DO PARANÁ. Documento oficial da Secretaria de Estado da Educação - Departamento de Ensino de $2^{\circ}$ Grau, maio de 1989.

FURTADO, Celso. Criatividade e dependência na civilização industrial. São Paulo : Círculo do livro, 1978, 169 p.

GRAMSCI, Antonio. In: MANACORDA, Mario A. O princípio educativo em Gramsci. Porto Alegre : Editora Artes Médicas Sul LTDA., 1990, 288 p.

MANNHEIM, Karl. Ideologia e utopia. 3.ed. Rio de Janeiro : Zahar, 1976, 330 p.

MARCUSE, R. Razão e Revolução. Rio de Janeiro : Editora Paz e Terra.

MERLEAU-PONTY, Maurice. O visivel e o invisível. São Paulo : Perspectiva, 1971, 330 .

NIETZCHE, Friedrich W. Assim falou Zaratustra: um livro para todos e para ninguém. São Paulo : Círculo do livro, Lineart, ed. 334 p.

PRITCHARD, Evans. Os Nuer.

REALE, Miguel. Estudos de Filosofia e ciência do direito: São Paulo : Saraiva, $1978,236 \mathrm{p}$.

RICOEUR, Paul. Interpretação e ideologias: org. trad. a apresentação de Milton Japiassu. Rio de Janeiro : Francisco Alves, 1983, 172 p.

ROTTERDAM, Erasmo de. Elogio da Loucura. Lisboa : Publicação EuropaAmérica, 1973, $245 \mathrm{p}$.

ROUSSEAU, Jean Jacques. $O$ contrato social.

THE DIALOGUES OF PLATO, translated by JOWETT, Benjamin. In: Encyclopaedia Britannica. Volume 7. Chicago-London-Toronto, 1975. 


\section{Anexo: "Apresentação do Currículo do Ensino de $2^{\circ}$ Grau" - Estado do Paraná - Secretaria de Estado da Educação - 1989 - Magistério.}

\section{Apresentação}

O documento ora apresentado resulta do trabalho que vem sendo desenvolvido pelo "Projeto de Avaliação Curricular da Habilitação Magistério" que integra o Programa de Reestruturação do Ensino de $2^{\circ}$ Grau, desenvolvido pelo Departamento do Ensino de $2^{\circ}$ Grau da Secretaria de Estado da Educação do Paraná, a partir de 1988.

O projeto tem como objetivo avaliar a proposta curricular implantada na rede estadual, avançando na construção de um currículo que altere $o$ atual quadro de indefinição e fragmentação da habilitação.

Nesta perspectiva é que em 1988, foram discutidas e elaboradas as propostas curriculares das disciplinas que abrangem a Parte Diversificada do Currículo da Habilitação. As propostas das disciplinas do Núcleo Comum foram elaboradas no bojo do Projeto de Conteúdos Essenciais, visando garantir a unidade do Ensino de $2^{\circ}$ Grau.

Foram envolvidos neste processo de discussão curricular, os Pólos de Magistério, Núcleos Regionais de Educação, Escolas de Magistério, Instituições de Ensino Superior e outras entidades da área educacional. Cabe destacar o papel fundamental dos profissionais da educação que atuaram como consultores no Projeto de Avaliação da Habilitação Magistério, cuja contribuição teórica assegura a cientificidade das diversas áreas do currículo.

Os documentos das propostas curriculares estão organizados de forma a abranger a concepção teórica, os conteúdos essenciais específicos, os aspectos metodológicos e as referências bibliográficas de cada disciplina.

$\mathrm{Na}$ efetivação do currículo, cabe ao professor organizar de forma significativa os conteúdos em cada área do conhecimento, situando-os sempre em relação às condições históricas de sua elaboração e desenvolvimento, bem como considerar a prática social do aluno de $2^{\circ} \mathrm{Grau}$ como referência para o desenvolvimento da ação pedagógica.

O presente documento registra mais uma fase no processo de alcançar a melhoria da formação do professor das séries iniciais não devendo, portanto, ser considerado "produto acabado" ou "guia curricular", 
que direcione todas as ações do professor, ou que cerceie sua criatividade. Deve servir antes, como ponto de partida das ações educativas e deve ser objeto de análise e chiscussão constantes, dado seu caráter histórico, provisório e que reflete as contradições da realidade em que se efetiva.

\section{O currículo do ensino de $2^{\circ}$ grau}

Ao longo da história, a luta pelo acesso à instrução, ao saber e à cultura tem figurado dentre as principais aspirações dos grupos sociais, notadamente das camadas majoritárias da população.

Dentre as lutas populares, percebe-se não apenas um movimento em prol da participação nos bens sociais, econômicos e culturais produzidos na sociedade capitalista, mas também a busca de uma redefinição social da classe trabalhadora que questione e desafie as práticas e concepções hegemônicas, na construção de uma sociedade democrática.

Encontra-se, ao longo da história da educação, diferentes tendências pedagógicas que ora privilegiam o docente, o método, o aluno, porém os conflitos maiores centram-se na legitimidade da produção do saber, envolvendo não só teorias da educação escolar, mas a teoria da produção e formação dos homens na história. Nesse sentido, a educação é entendida numa perspectiva de "construção histórica", inseparável das relações sociais produtivas do cotidiano.

Portanto, a escola tem refletido, no seu dia-a-dia, as marcas contraditórias desta sociedade, impressas pelo conjunto de determinações sociais e adquire, ao mesmo tempo, especificidades enquanto agência socializadora de produção do saber. Faz-se necessário então, garantir o sentido da escola democratizada no Estado do Paraná.

Democratizar a escola significa melhorar as condições de acesso e permanência do alunado, bem como ofertar um ensino de melhor qualidade. Esta melhoria está vinculada à questão do conhecimento, sua reconstrução, essencialidade e revisão da prática pedagógica.

$\mathrm{O}$ acesso à escola de $1^{\circ} \mathrm{Grau}$ continua a ser prioritário no país, mas também é imperativo à generalização do ensino de $2^{\circ} \mathrm{Grau}$. A importância desse grau de ensino cresce concomitantemente à complexificação porque passa a sociedade brasileira, e pelo fato que, nos últimos anos, segmentos significativos das camadas majoritárias da população têm procurado o $2^{\circ}$ Grau na tentativa de inserção no mercado de trabalho. $\mathrm{Na}$ visão de Miguel Arroyo, a luta pelo saber acaba sendo o modo pelo qual o povo entra na história e se constitui cidadão. 
A questão central reside em repensar o ensino de $2^{\circ}$ Grau como condição para ampliar as oportunidades de acesso ao conhecimento e, portanto, de participação social mais ampla do cidadão. Este repensar passa, necessariamente, pela análise das relações entre a escola, o trabalho e a cidadania.

Historicamente, o que se pode perceber é um duplo processo de expropriação: material e intelectual. $\mathrm{O}$ trabalho é dimensão fundamental da vida humana e se faz presente em todas as ações e atividades do homem, tendo uma dimensão dinâmica e libertadora, na medida em que modifica as condições materiais de existência, suas formas de pensar e agir. Por outro lado, pode constituir-se num elemento de alienação, quando não é permitido ao trabalhador alcançar o processamento da produção em seu conjunto, nem a essência criadora do ato de trabalho, que comporta possibilidades de iniciativa, de reflexão e de decisão. É no mundo do trabalho que se situa o "locus" da unidade teórica e prática, pontos de partida e de chegada da ação educativa.

A questão da preparação para o trabalho deve ser pensada a partir da especificidade da educação escolar e dos limites da escola. Repensar a relação trabalho e educação exige que se aprofundem as formas que estas vão assumindo, além da natureza das contradições que emergem destas relações. A presença mais marcante do trabalho na escola se dá na mediação dos conhecimentos acumulados historicamente pelo homem e, especialmente, dos conhecimentos científicos e tecnológicos que, quando produzidos, dão respostas concretas aos problemas enfrentados pelo homem em seu caminhar. Nesse sentido, a história do conhecimento é a própria história do trabalho.

Segundo Saviani (1986), no $2^{\circ}$ Grau, não basta dominar os elementos básicos e gerais do conhecimento, é preciso também explicitar como o conhecimento converte-se em potência material no processo de produção.

Nesta perspectiva, o Ensino de $2^{\circ} \mathrm{Grau}$, deve propiciar aos alunos o domínio dos fundamentos das técnicas diversificadas, utilizadas no processo de produção e não o mero adestramento de técnicas produtivas. Esta concepção está a exigir medidas a curto, médio e longo prazo, voltadas ao suprimento e apoio à rede estadual de ensino, visando propiciar meios para que ela cumpra suas funções e atinja plenamente seus objetivos, incluindo medidas de avaliação da atual política educacional, como também das estratégias utilizadas para viabilização das práticas pedagógicas.

O desafio está no sentido de avançar na compreensão do que significa o caráter mediador da escola de $2^{\circ}$ Grau para as camadas ma- 
joritárias da população. Impõe-se como fundamental, a criação de uma proposta pedagógica que propicie o acesso ao saber enquanto totalidade, reunindo teoria e prática.

Por outro lado, importa reconhecer que os alunos deste grau de ensino, principalmente os que freqüentam a escola noturna, já estão inseridos no processo produtivo.

A postura de uma escola democrática visa a preparação do educando para a democracia, elevando sua capacidade de compreensão em relação aos determinantes políticos, econômicos e culturais que regem o funcionamento da sociedade em determinado período histórico, para que venha atuar no mundo do trabalho com a consciência de seu papel de cidadão participativo.

Para que esta condição se efetive, a escola deve assegurar a sua função de ensinar bem e de forma sistematizada, garantindo a formação do cidadão pelo domínio do saber.

PROPOSTAS DAS DISCIPLINAS - Intituladas "Projeto de Avaliação da Proposta Curricular da Habilitação Magistério" 1989.

\section{PROPOSTA DA DISCIPLINA: "FILOSOFIA DA EDUCAÇÃO".}

\section{Introdução}

A Filosofia da Educação deve explicitar as teorias que fundamentam a prática pedagógica e sua derivação de determinadas visões de mundo, concepções de sociedade e de homem e suas diferentes linhas epistemológicas.

Desta forma ela pode fornecer ao professor um método de reflexão sobre os problemas da educação, capaz de superar o caráter fragmentário do senso comum, a parcialidade do método positivista, possibilitando uma visão crítica da realidade, que permita uma ação transformadora, levando-se em conta o homem que se quer formar e o tipo de estrutura social que o determina.

O pressuposto em cima do qual se organizou o programa é a relação da reflexão filosófica com a prática pedagógica, ou seja, a relação entre a filosofia enquanto compreensão e guia da ação educativa e esta como fundamento e limite do pensamento pedagógico. 
Esta relação deve ser compreendida na dimensão histórica em que ela se realiza: uma realidade concreta, uma sociedade concreta, um professor e um aluno concretos.

É a partir dessa dimensão histórica que se estabelecem as relações entre Filosofia e Filosofia da Educação e entre Filosofia da Educação e Pedagogia que nortearam esta proposta.

O programa de Filosofia da Educação está concebido e deve ser dimensionado, portanto, considerando:

1. a reflexão sobre os aspectos sociais. que condicionam o pensamento filosófico e pedagógico;

2. a reflexão sobre o movimento dos aspectos internos a esse pensamento.

O caráter histórico do pensamento filosófico, já explicitado anteriormente, implica em que a reflexão filosófica da educação não se dá a partir de um ponto de vista qualquer, supostamente neutro. A teoria produzida é, explicitamente ou não, conscientemente ou não, interpretação e reflexão que o homem faz em, e a partir de uma prática que é social e histórica, portanto situada. A Filosofia, reafirmamos, mesmo quando o nega, tem como função não a "contemplação do mundo", mas a direção da ação, seja para manter ou para transformar o ordem social vigente.

Esta proposta se direciona no compromisso de uma democratização da escola brasileira e, como conseqüência, com a formação de um professor capaz de compreendê-la, em totalidade, na sua inserção na sociedade brasileira atual, no caráter mediador que ela assume na direção da transformação desta sociedade. (Segue a proposta de conteúdos programáti$\cos )$.

Proposta da disciplina: "Sociologia da Educação".

Introdução

A proposta aqui apresentada, já configura a necessidade de mudanças, não só de enfoque, mas do próprio conteúdo, isto já materializado no diagnóstico feito pela SEED do Paraná.

Dois são os pressupostos que justificam a abordagem.

$\left.1^{\circ}\right)$ Necessidade de se reforçar a formação básica do profissional e em especial a formação nas Ciências Humanas.

$2^{\circ}$ ) Necessidade de reforçar a formação específica do profissional que vai atuar nas séries iniciais do $1^{\circ} \mathrm{Grau}$. 
O programa de Sociologia tem como objetivo na formação geral, a compreensão da realidade social e das forças sociais que nela atuam.

$\mathrm{Na}$ formação específica do profissional que deverá atuar nas primeiras séries, o objetivo é a compreensão da própria escola, no meio em que está e nas suas relações con. a Sociedade; na análise da Educação, utilizando o conceito de educação relacionado com o conceito social e político, inserido nas relações sociais capitalistas. Educação como opção política por um tipo de ensino que venha a atender aos interesses das camadas majoritárias da população.

Para se operacionalizar esta propost ś necessário que se possa garantir nos programas:

1 - Conhecimentos básicos específicos da Sociologia, diferenciandoa das outras ciências.

2 - Conhecimentos sociológicos, necessários para a compreensão das relações sociais na Sociedade Capitalista.

3 - Análise que possibilite a compreensão da educação como opção política, por tipo de ensino, portanto como prática social e a escola como uma das práticas.

Se o programa de Sociologia for assim concebido, será um programa crítico que enfatizará a ciência como um processo de conhecimento e não como algo acabado, porque a ciência nunca é neutra, mas comprometida.

A partir desses pressupostos, podemos apontar alguns eixos para o programa da Sociologia da Educação.

- Estudo das origens da Sociologia.

(seu surgimento, nasce na revolução industrial - capitalismo).

- Concepções de que a ciência não é neutra, e por isso as teorias se constroem a partir de concepções que cada autor tem da Sociedade - há sempre um componente político e ideológico. (Segue a proposta de conteúdos programáticos).

Proposta da disciplina: "História da Educação" - concepção de História da Educação.

Este texto tem como finalidade oferecer algum suporte, em termos de fundamentação, aos educadores e/ou futuros educadores comprometidos com a formação de professores de $1^{\circ}$ Grau. Isto é, temos como objetivo proporcionar um instrumento a mais para os educadores identificados com a Habilitação Magistério ao nível de $2^{\circ}$ Grau, no sentido de uma reflexão acerca da História da Educação Brasileira 
Sabemos que uma perspectiva globalizante, relativa aos problemas educacionais e pedagógicos no eixo da história brasileira só contribui para uma prática educativa (talvez social) mais coerente, sistemática e eficaz, e, com certeza, mais conseqüente.

$\mathrm{Na}$ verdade, essa introdução é necessária, na medida em que referenda uma programação de curso e assume, por assim dizer, sua paternidade.

Ao considerarmos concretamente a carga horária de História da Educação, no "Curso de Formação para o Magistério de $1^{\circ} \mathrm{Grau}$ " tendo em vista sua necessária articulação com o conjunto das demais disciplinas nucleares que totalizam o chamado currículo, compreendemos sua função instrumentalizadora. Tal função se consolida na proporção em que se identifica como uma ampla abordagem metodológica viabilizadora da apreensão das articulações entre:

a) o campo educacional e as diversas teorias pedagógicas;

b) conflitos de classe e as contradições presentes ao longo do processo de complexificação da formação social brasileira.

Menos do que uma lista de temas sonhados pairando além das condições concretas da práxis educativa de nossa sociedade, essa proposta curricular tem a pretensão de contribuir com uma espécie de "óculos metodológico" testado ao longo da prática da sala de aula que contribuirá, talvez, para um começo de entendimento da historiografia e da realidade histórica da educação brasileira.

Não obstantemente, acreditamos como primordial, para estudantes e professores, enfim para os intelectuais, a compreensão da educação integrada a uma perspectiva histórica. Nessa premissa, a.História da Educação Brasileira se coloca como conteúdo imprescindível na Formação do Magistério ao nível do $2^{\circ}$ Grau. Se levarmos em conta ainda, que essa oportunidade foi roubada por força dos desígnios ditatoriais, de uma geração inteira de professores e ocultada sob o caldo insosso apelidado de Fundamentos da Educação, não podemos, sob qualquer alegação teórica ou preconceito técnico, secundarizar a História da Educação Brasileira. Obviamente devemos priorizá-la. Do contrário, seremos julgados ao lado dos causadores do desastre cultural perpetuado desde o golpe de 64 . Heróis-vítimas da resistência devemos, pelo menos, reconquistar o direito $\mathrm{da}(\mathrm{o})$ normalista, entre tantas dificuldades para estudar nesta terra, compreender porque foi educada $(0)$ de um modo determinado em um país usurpado pelos interesses de grupos específicos e calcinado pela burocracia da Ditadura Militar. 
Sem esse compromisso político qualquer conteúdo disciplinar se esvazia e não há competência técnica que lhe garanta, isoladamente, significado teórico, isto é, esse olhar sobre o mundo dos homens, esse passaporte para a cultura erudita onde se descortina a compreensão da educação como um elemento mutável, construído e em construção pela luta dos homens, em síntese, como algo histórico.

- Então, quem conhece a História?

- Em certo sentido todos os homens. Mesmo que não tenham lido qualquer compêndio específico, ou sequer saibam ler.

Todos têm uma filosofia de vida, possuem uma determinada concepção de mundo capaz de indicar, orientar a interpretação ativa do dia-adia de cada um. Uma espécie de colméia íntima segregadora de uma forma de consciência relativa dos acontecimentos que nos circundam e compõem nossas vidas. Acontecimentos esses que já ocorreram, que estão ocorrendo, ou que irão ocorrer, e que de alguma forma todos se percebem, nesses mesmos acontecimentos como atores, principais ou coadjuvantes, ou, muitas vezes a contragosto, como meros espectadores.

É nesse sentido que dizemos que no âmago da concep̧̧ão de mundo de todos e de cada um se encontra, também, um sentido de história, isto é, um referencial que possibilita interpretar o passado como tal, decodificar e atuar nas condições do presente, bem como ter aspirações rélacionadas com o füturo.

Quando entendemos e aceitamos todos os homens como portadores de uma determinada concepção de mundo, não se torna forçada a afirmação decorrente que todas as pessoas sabem história.

Nesse instante lembramo-nos do rodapé do velho exemplar, repetidamente sublinhado, da sempre atual Ideologia Alemã:

"Apenas conhecemos uma ciência, a da História". É sem dúvida uma concepção firme e precisa para orientarmos a presente fundamentação e compreendermos que, tanto professores e alunos, quanto as demais pessoas, possuem representações do mundo real e sensível das quais independente e antecipadamente a qualquer estudo rigoroso e sistemático, configurar de modo determinado suas próprias interpretações históricas. Fenômeno que não se constitui em um obstáculo absolutamente intransponível.

As interpretações referidas acima, geralmente denotam parcialidades, esquematismos e incoerências relacionadas com a concepção dominante de mundo, as quais caracterizam, muitas vezes, sua particular inserção na estrutura de classe de uma formação social determinada. 
Dizemos, nesses casos, que prevalece nele o senso comum, berço das representações condicionadas pelas divisões da sociedade em classes, isto é, uma perspectiva fragmentada da totalidade social.

Não percebemos uma reflexão sistematizada, rigorosa e de conjunto sustentando dada interpretação.

Não obstante ao imobilismo doentio, ou ao ativismo galopante a que as concepções do senso comum conduzem a prática social das pessoas, de um modo geral, no cerne de suas interpretações e relações com o mundo que as rodeia, encontraremos sempre algo válido e recuperável - o bom senso - que deve ser trabalhado pela educação escolar com o objetivo de alçar o aluno a ação-reflexão, sistematizada, rigorosa e de conjunto. Em suma, à interpretações científicas.

É no âmbito do senso comum que encontramos as percepções históricas mais usuais. As que enxergam o desenrolar da história como um simples e inexorável suceder de fatos justapostos os quais fatalisticamente chegarão a um término, ou algo assim; aquelas que percebem o caminhar histórico como sendo repetitivo à semelhança de um disco arranhado cuja reprodução da melodia, em determinado ponto , volta ao mesmo lugar, também parecendo os "enlatados" americanos ou novelas de TV..., onde mudam os artistas mas a história é sempre a mesma: pobres e ricos, bandido e mocinho, ela, ele, o outro e variações, patrões e empregados, etc.; finalmente, as representações que entendem o ciclo histórico como uma seqüência de etapas de apogeu e declínio de povos, raças e nações. Nessa concepção, ao ponto culminante de progresso e crescimento das sociedades corresponde, em seqüência inexorável, um período de penúria e decadência.

Tanto a perspectiva da sucessão encadeada de fatos, quanto a repetição cíclica, supõem que "as coisas" já estão postas de um dado modo ..." que o mundo (a vida) é assim mesmo"... e que só nos resta "viver da melhor forma possível nosso destino, sem incomodar"... principalmente os que estão acima de nós, os poderosos, assim ficaremos "felizes" com o que porventura nos sobra deles. A última representação a que nos referimos no parágrafo anterior é própria das interpretações voluntaristas e violentas, que assumem posturas patrióticas, desígnios de raça e dogmas místico-religiosos. Em nome dessa perspectiva as soluções drásticas e belicosas são justificadas para que cheguemos ao cume do nosso destino e ali nos mantenhamos, visto que, inevitavelmente a hora da decadência chegará pelas mãos dos invejosos de nossa superioridade.

Essas concepções não existem exclusivamente de forma isolada. Elas se constituem basicamente em um verdadeiro amálgama com ex- 
pressão e existência real ( consciente ou imaginária) nas pessoas, nos grupos, nas famílias, nas corporações, nos "bate-papos" inocentes, nos discursos, nos documentos oficiais, nas escolas, nas fábricas e hospitais, em suma, no nosso mundo de relações sociais.

Tal amálgama de representações sobrevive no interior de todas as camadas sociais correspondendo de forma variada e difusa, através de uma linguagem simples ou sofisticada, porém de maneira sempre precisa, aos interesses das classes dirigentes da sociedade. Significa, para tais classes, um fator decisivo no processo de dominação destas sobre as demais camadas da sociedade na medida em que é assimilada indiscriminadamente. Trata-se da ideologia dominante.

Entretanto, existe uma concepção de História, não tanto disseminada na vida social, cindida dessa ideologia. Essa concepção não encontra respaldo nas classes dominantes: trata-se da concepção em que o processo histórico ocorre sem predestinações. Desenvolve-se por força dos confrontos entre classes sociais. Assim, na proporção em que a maioria constituída pelas camadas menos privilegiadas, no movimento dos confrontos de seus interesses com os interesses da classe dominante registra conquistas, dizemos que houve avanços, do contrário, quando os interesses da maioria são obstruídos e/ou aniquilados, dizemos que houve recuo e retrocesso no desenvolvimento da história.

Nessa concepção não há fatalismos ou interpretações escatológicas. São os homens que constroem sua história ao produzirem sua própria existência material. Os homens, nessa gigantesca constrúção, sob condições naturais e materiais determinadas, evoluíram - entre avanços e recuos - do machado de pedra ao computador. Ao longo dessa evolução e conseqüente complexificação do processo de produção de sua existência os homens foram ocupando e dividindo posições específicas, tendo em vista o controle e a organização da coletividade. Ao mesmo tempo que importantes para a sociedade, o controle e a organização do processo de produção também fomentaram, a partir da posição ocupada no referido processo, o confronto de interesses entre os homens. É, justamente ao longo da dinâmica desse confronto, inevitável a todos os participantes das formações sociais, que tem origem a divisão histórica dos homens em grupos ou classes.

Essas classes com interesses divergentes vêm se antagonizando, se mobilizando, tomando posições, se entrechocando, estabelecendo movimentos que dão origem à própria história.- bem, isso quer dizer que todos nós, além de conhecermos, também somos história? 
- Exatamente. Estudar História, na verdade, é buscar a compreensão e o conhecimento do homem. É um esforço de descoberta de nós mesmos. Portanto, para descobrirmos mais sobre nós é necessário estudar o homem, mas não abstratamente, separado de suas condições reais de sobrevivência e do conjunto das relações sociais onde produz sua existência. Concretamente o homem é a síntese das múltiplas relações que foram e vem sendo estabelecidas ao longo da história. Nesse sentido podemos dizer que as relações sociais engendram os homens, pois são relações forjadas no desenvolvimento da história do homem.

- Podemos concluir, a partir de tudo isso, que o estudo da História da Educação é um segmento do estudo de própria história?

- Devemos cuidar para não esquecer que a Educação, enquanto processo, tem um lugar privilegiado no contexto histórico, pois se integra na história do homem na medida em que participa, em todas as instâncias da dinâmica social, política, econômica e cultural. Não devemos nos perder nos detalhes específicos da História da Educação ou da Pedagogia, para podermos encontrar, na magnitude do processo histórico global, o esplendor da educação enquanto produto das lutas dos homens. 